\title{
Relationships Between Enamel Prism Decussation and Organization of the Ameloblast Layer in Rodent Incisors
}

\author{
LÉANIE ALLOING-SÉGUIER, ${ }^{*}$ LAURENT MARIVAUX, ${ }^{1}$ \\ JEAN-FRANCOIS BARCZI, ${ }^{2}$ FABRICE LIHOREAU, ${ }^{1}$ AND \\ CAMILLE MARTINAND-MARI (D) ${ }^{*}$ \\ ${ }^{1}$ ISEM, Université de Montpellier, CNRS, IRD, EPHE, Montpellier, France \\ ${ }^{2}$ AMAP, Université de Montpellier, CIRAD, CNRS, INRA, IRD, Montpellier, France
}

\begin{abstract}
Rodent enamel microstructure has been extensively investigated, primarily on the basis of $2 \mathrm{D}$ electronic microscopy data. The nature and dynamics of the ameloblasts (the enamel-secreting cells) have also been well studied. However, critical issues still remain surrounding exactly how the ameloblasts produce the astonishing microstructural complexity of enamel, and how this subtle architecture evolved through time. In this article, we used a new methodology based on confocal laser microscopy to reconstruct the enamel microstructure of rodent incisors in three dimensions (3D) with the ameloblasts in situ. We proposed interpretations regarding the possible relationships between the workings of the ameloblasts and the resulting enamel prisms, especially how the phenomenon of decussation is generated. Finally, we were able to represent the two main types of modern rodent incisor microstructures (uniserial and multiserial decussations), as a set of parameters that have been entered into the 3D enamel simulation software Simulenam to generate 3D models that can be digitally manipulated. Associating 2D data of incisor enamel microstructure of fossil rodents and Simulenam, it was then possible to better understand how the various decussation parameters evolved through time and gave rise to the two modern microstructure types from the same ancestral type (pauciserial). This study also confirmed that rodent and artiodactyl enamel do not share the same mechanism of decussation formation. Anat Rec, 302:11951209, 2019. (C) 2018 Wiley Periodicals, Inc.
\end{abstract} Key words: Rodentia; enamel microstructure; simulation;
enamel evolution

A prominent feature of mammalian dental enamel microstructure is the presence of enamel prisms or rodsbundles of closely packed hydroxyapatite crystallites, running from the enamel-dentine junction (EDJ) toward the outer enamel surface (OES), and surrounded by an inter-prismatic matrix (IPM, also called "interrod
Additional Supporting Information may be found in the online version of this article.

Grant sponsor: Research Council of the University of Montpellier; Grant sponsor: Interrvie program of the INSU CNRS; Grant sponsor: SPLASH, research program; Grant number: ANR-15CE32-0010-01.

*Correspondence to: Léanie Alloing-Séguier, Université de Montpellier, ISEM, UMR5554, Bat 22, Place Eugène Bataillon, 34095 Montpellier cedex 5, France. Tel: +33 (0)4 671433 75; Fax: +33 (0)4 673622

E-mail: lea.alsey@gmail.com and

Camille Martinand-Mari, Université de Montpellier, ISEM, UMR5554, Bat 22, Place Eugène Bataillon, 34095 Montpellier cedex 5, France. Tel: +33 (0)4 671433 75; Fax: +33 (0)4 673622

E-mail: camille.martinand-mari@umontpellier.fr

Received 8 January 2018; Revised 21 June 2018; Accepted 5 July 2018.

DOI: $10.1002 / a r .24000$

Published online 26 October 2018 in Wiley Online Library (wileyonlinelibrary.com). 
enamel"). Enamel is secreted by a specialized epithelial cell type of ectodermic origin, the ameloblast (for review, see Habelitz, 2015). Prisms are formed by a peculiar cytoplasmic expansion located at the functional apical pole of the ameloblast, the Tomes' process, while the IPM is produced by the apical surface not occupied by the Tomes' process (Kallenbach, 1973; Leblond and Warshawsky, 1979; Simmer et al., 2012; Nishikawa, 2017). It is commonly thought that each ameloblast secretes one prism, running from the EDJ toward the OES (Boyde, 1964, 1967; Osborn, 1970a;Kallenbach, 1973 ; Line and Novaes, 2005). The orientation and growth of the crystallites constituting a prism are guided by molecular assemblies, notably amelogenin nanospheres and microribbons (Du et al., 2005; Margolis et al., 2006; Yang et al., 2010). However, the orientation of the prism itself results from the orientation of the Tomes' process (Kallenbach, 1973; Line and Novaes, 2005). The ameloblast layer migrates away from the dentine during enamel secretion, or secretory phase, and thus, a prism is supposed to represent a "fossil trace" of the path of its secreting ameloblast from the EDJ toward the OES. When the entire thickness of enamel has been secreted, ameloblasts begin the maturation phase, resorbing their Tomes' process, and taking an active part in the mineralization process (Warshawsky and Smith, 1974; Lacruz et al., 2013).

Enamel prisms can be organized homogeneously, with parallel courses, as in radial enamel, or they can form decussated enamel. Decussation is typically characterized by alternating bands or patches of longitudinally and transversely sectioned prisms as observed on $2 \mathrm{D}$ sections of enamel (Fig. 1A). Multiple types and configurations of decussation have been recognized and are usually grouped under the designation of "HunterSchreger Bands" (HSB); for example: transverse HSB (most common type, present in various mammalian lineages, including primates, carnivorans, cetartiodactyls and perissodactyls; e.g., Pfretzschner, 1993; Maas and Dumont, 1999; Stefen, 1999; Alloing-Séguier et al., 2014), vertical and compound HSB (some rhinocerotoid perissodactyls and astrapotheres; e.g., Rensberger and Pfretzschner, 1992; Koenigswald et al., 2011), slanted HSB (some cetartiodactyls; Alloing-Séguier et al., 2014), zigzag or "level II" HSB (suggested to be linked to osteophagia; Rensberger, 1999; Stefen, 1999), pauciserial, multiserial, and uniserial "HSB" (rodents; e.g., Martin, 1993, 1999).

It has been suggested early on (i.e., Raschkow, 1835) that the formation of decussation could result from a movement of ameloblasts. Subsequent authors reached the same conclusion (e.g., Jasswoin, 1924; Meyer, 1935; Butcher, 1956), but since then only a few hypotheses of how this movement is performed have been proposed (Waldeyer, 1870; Süss, 1940; Wolf, 1942), the model of Boyde $(1964,1967,1997)$ and the model of Osborn (1970a, 1970b, 1990) being the most prevalent in the literature.

Boyde (1964) proposed two hypotheses for a mechanism of ameloblast movement in his thesis (Boyde, 1964). In essence, his "crossing model" proposes that rows of ameloblasts would slide against each other, and produce prisms maintaining a constant orientation that effectively cross each other in the enamel thickness (one prism can only be sectioned longitudinally or transversely). In the first hypothesis, this sliding is actively initiated and maintained by the ameloblast itself. In the second, more favored by the author, the Tomes' process is anchored in enamel, only one
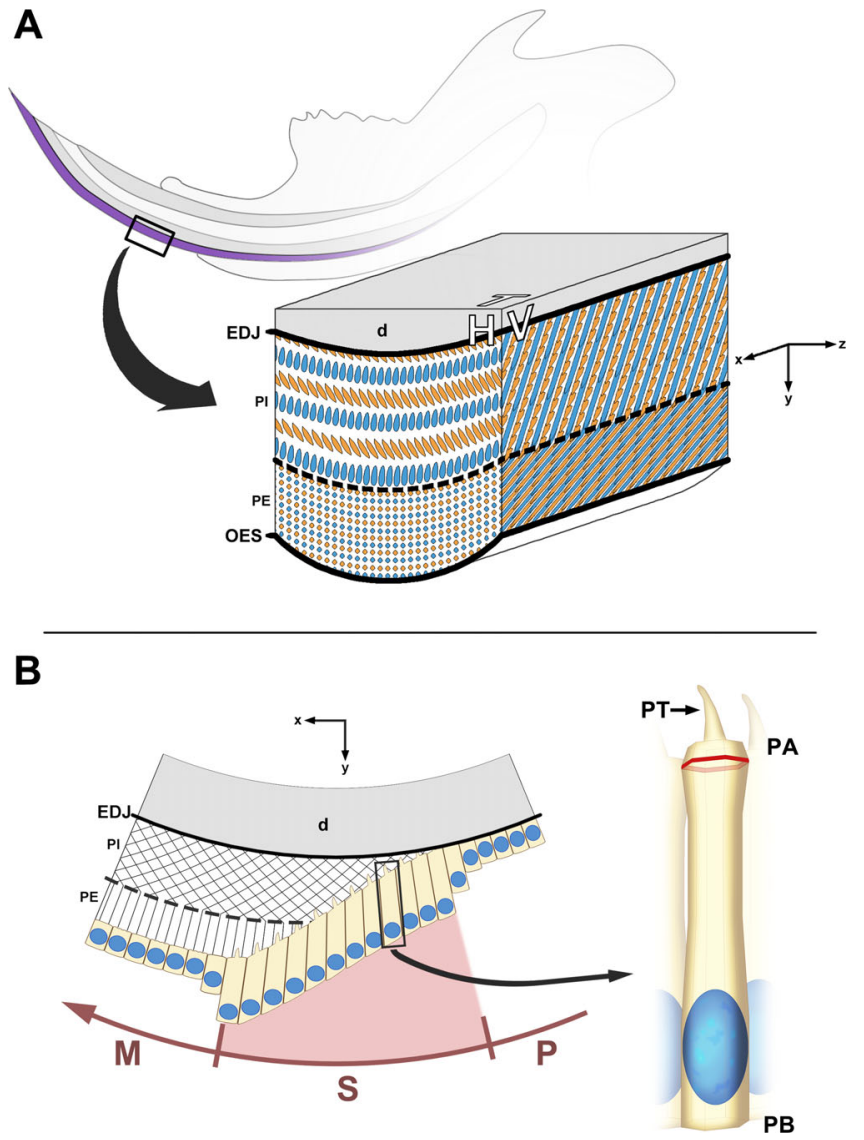

Fig. 1. Enamel microstructure and the ameloblasts. (A) Schematic representation of the microstructure of the lower incisor enamel of a rodent with uniserial decussation. The enamel layer is located on the ventral side of the incisor (purple), and extends from the Enamel-Dentine Junction (EDJ), in contact with the dentine (d, in light gray), to the Outer Enamel Surface (OES). Microstructure in rodents is typically subdivided into a portio interna (PI) with decussated enamel and a portio externa (PE) with radial enamel (separated here by a dashed line). Prisms can be of two orientation types (one blue, one orange), and are separated from each other by the Inter-Prismatic Matrix (IPM, in white). The three main section planes are the Vertical/sagittal (V, on plane $(x y))$, the Horizontal/ frontal $(H$, on plane $(y z))$, and the Tangential (T, on plane $(x z))$. (B) Schematic representation of the ameloblast layer (yellow) during amelogenesis (left), with details of a secretory ameloblasts (right). Enamel secretion is composed of three successive phases: (i) the pre-secretory phase $(P)$, with undifferentiated ameloblasts, (ii) the secretory phase (S, relevant zone in pink) where ameloblasts differentiate, gain their Tomes' process (PT), and produce enamel, first the PI then the PE, and (iii) the maturation phase (M), during which the Tomes' process is lost. The secretory ameloblasts are elongated cells, with the nucleus located near the basal pole $(\mathrm{PB})$, while the Tome's process is an extension of the functional apical pole (PA). The "apical level" where measurements of ameloblasts were performed is represented as a red band. d: dentine.

side of the process is active, and thus, the ameloblast is passively pushed in the direction opposite to this secretory side by the apposition of new enamel. More recently, however, Boyde (1997) seemed to tend more toward his first hypothesis of active movement.

The model of Osborn (1970a, 1970b, 1990), in contrast to Boyde's hypotheses, proposes a "sinusoidal model" where rows of ameloblasts experience a rhythmic sinusoidal deformation that gives rise to prisms of variable 
orientation (one prism can successively be sectioned longitudinally and transversely). This deformation would be a consequence of enamel secretion, with the force of reaction of the secreted enamel opposing the secretory force of the ameloblast by pushing the cell outward, and also inducing a sinuous movement to the ameloblast itself. This bending of the cell would be transferred to its neighbors, as they are closely packed, thereby affecting the whole ameloblast row. Instead of crossing, sinusoidal prisms are slightly offset with respect to their neighbors.

In a previous study (Alloing-Séguier et al., 2017), we evaluated the crossing and sinusoidal models through a new enamel microstructure simulation software, Simulenam, as there was not a clear-cut view of which one should be favored for studying prism decussation in our group of interest, hippopotamoids (Cetancodonta, Cetartiodactyla). The sinusoidal model proved to be the most accurate one to reconstruct the microstructure of this group, but some published results (notably Warshawsky and Smith, 1971) still validate a crossing model for at least one type of decussation found in rodents (uniserial decussation). This suggests that the diversity of mammalian enamel microstructure cannot be reduced to a single model of decussation formation, and that each HSB configuration could represent a distinct developmental pathway of decussation generation.

In the present study, we decided to explore the crossing model further with Simulenam on the basis of the enamel microstructures of living rodents, specifically enamel of the lower incisors. We designed a new methodology of 3D reconstruction capable of extracting information for both prisms and ameloblasts in the same sample, assuring the correspondence between the two. With observed 3D relationships, it was possible to include them in Simulenam and, on the basis of $2 \mathrm{D}$ morphological data, to explore rodent microstructure and its development in an evolutionary context.

\section{MATERIAL AND METHODS}

\section{Sample}

This study was carried out in strict accordance with European and French legislations (directives 2010/63 and
2016-XIX-120, respectively) for the care and use of animals for scientific purposes (ISEM agreement No. A34-172-042). We selected two extant rodent species, one with an incisor enamel microstructure showing uniserial decussation, the house mouse Mus musculus (Muridae), and another displaying an incisor enamel with multiserial decussation, the coypu Myocastor coypus (Myocastoridae). We also sampled a marsupial, the opossum Didelphis marsupialis, which shows an incisor enamel microstructure characterized by radial enamel. Our sample (see Table 1) included one 5-day old, two 10-day old, and two adult mice from the "Conservatoire Génétique de la Souris Sauvage" (ISEM, Montpellier, France), two coypu fetus (95 gestation days) trapped in the south of France (Camargue; from "Biologie-Écologie" Education department, Université de Montpellier, France, agreement No. DDTM34 34S2887), and an opossum fetus trapped from French Guyana (40 to 70 gestation days; ISEM agreement No. A34-172-042).

Individuals were selected according to their age (mandibles of younger individuals are less mineralized and easier to section as a result) and body size (this parameter was constrained by the decalcification equipment at our disposal). We analyzed incisors specifically because this tooth is ever-growing in rodents, thereby giving access to all the successive stages of enamel development on a single tooth. The inferior incisor was favored over the superior one, because of its ease of extraction, less curved crown, and lack of relief.

Additionally, exploring the evolution of decussation parameters required the sampling of fossil rodent taxa to perform typical 2D microstructure data observations. We selected isolated incisors of two Eocene rodents, Glibia sp. (Zegdoumyidae) from the Glib-Zegdou Formation (Algeria; see Marivaux et al., 2011), and cf. Protophiomys tunisiensis (Hystricognathi) from the Djebel Kebar (Tunisia; see Marivaux et al., 2014). Inferior incisors of both taxa exhibit primitive stages in the development of the uniserial and multiserial decussation types from the pauciserial ancestral type: the microstructure of Glibia sp. displays a strong uniserial tendency, while the microstructure of $c f$. Protophiomys tunisiensis is a multiserial much less derived than the one of Myocastor coypus. Finally, we also sampled

TABLE 1. Summary of studied species

\begin{tabular}{|c|c|c|c|c|c|}
\hline $\begin{array}{l}\text { Number of } \\
\text { specimens }\end{array}$ & Species & $\begin{array}{l}\text { Developmental } \\
\text { stage }\end{array}$ & Geographic origin & $\begin{array}{l}\text { Temporal } \\
\text { expansion }\end{array}$ & $\begin{array}{l}\text { Decussation } \\
\text { type }\end{array}$ \\
\hline 1 & Mus musculus & 5 days & $\begin{array}{l}\text { Wild Mouse Genetic Repository, } \\
\text { Montpellier, France }\end{array}$ & Extant & Uniserial \\
\hline 2 & Mus musculus & 10 days & $\begin{array}{l}\text { Wild Mouse Genetic Repository, } \\
\text { Montpellier, France }\end{array}$ & Extant & Uniserial \\
\hline 2 & Mus musculus & Adult & $\begin{array}{l}\text { Wild Mouse Genetic Repository, } \\
\text { Montpellier, France }\end{array}$ & Extant & Uniserial \\
\hline 2 & $\begin{array}{l}\text { Myocastor } \\
\text { coypus }\end{array}$ & $\begin{array}{l}95 \text { days of } \\
\text { gestation }\end{array}$ & Camargue, Hérault, France & Extant & Multiserial \\
\hline 1 & $\begin{array}{l}\text { Didelphis } \\
\text { marsupialis }\end{array}$ & $\begin{array}{l}40-70 \text { days of } \\
\text { gestation }\end{array}$ & French Guyana & Extant & Radial \\
\hline 1 & Glibia sp. & & Algeria (Marivaux et al., 2011) & $\begin{array}{l}\text { Early Late to early } \\
\text { Middle Eocene }\end{array}$ & $\begin{array}{l}\text { Transitional } \\
\text { Pauciserial-Uniserial }\end{array}$ \\
\hline 1 & $\begin{array}{l}\text { Protophiomys } \\
\text { tunisiensis }\end{array}$ & & Tunisia (Marivaux et al., 2014) & Late Middle Eocene & Multiserial \\
\hline 1 & Cocomys sp. & & $\begin{array}{l}\text { Louisiana Museum of Natural } \\
\text { History, LA, USA (Martin, } \\
\text { 2007) }\end{array}$ & Early Eocene & Pauciserial \\
\hline
\end{tabular}

Enamel data for additional taxa are taken from the literature as indicated. 
three inferior incisors of adult Mus musculus individuals for $2 \mathrm{D}$ study, to compare the typical $2 \mathrm{D}$ data with the results of our new 3D methodology (see Table 1).

\section{Methods}

Dissected mandibles were fixed for 2 days at $4^{\circ} \mathrm{C}$ with $4 \%$ paraformaldehyde (PFA) in phosphate buffered saline (PBS), then decalcified at $50^{\circ} \mathrm{C}$ in a microwave for at least $72 \mathrm{hr}$ with a $4.13 \%$ ethylene diamine tetraacetic acid (EDTA) and $0.2 \%$ PFA solution. Serial slices $50 \mu \mathrm{m}$ thick were performed with a vibratome, along the sagittal or frontal plane, and later permeabilized for 30 min with $0.3 \%$ Triton in Tris Buffer Saline (TBS) solution.

To improve the quality of Myocastor coypus slices, dissected and fixed mandibles of one fetus were dehydrated in ethanol row and a final xylene step, and subsequently embedded into Methyl-Methacrylate (Sigma-Aldrich, LLS Rowiak LaserLabSolutions). Serial sections, obtained by lasermicrotome TissueSurgeon (LLS Rowiak LaserLabSolutions), were deplastified in Methyl methacrylate overnight and washed in Shandon Xylene Substitute (Thermo Scientific) before their rehydration and staining.

Slices were stained with DAPI (nuclei staining) at $500 \mu \mathrm{g} / \mathrm{L}$ and either $0.01 \%$ TRITC or $1 \%$ phalloidin-TRITC (for membrane actin staining; Sigma-Aldrich), and were analyzed with a Leica DM 2500 laser confocal microscope (Montpellier RIO Imaging platform, France) to acquire three-dimensional data, represented by image stacks (about 300 frames for a single $50 \mu \mathrm{m}$-thick slice acquisition with a $0.13 \mu \mathrm{m}$ step between frames). Stacks were then exploited with the software Avizo 7.1 (VSG Inc.) by segmenting the prisms into $3 \mathrm{D}$ objects and taking measurements of prism and ameloblast size and decussation angles. The Fiji software (Schindelin et al., 2012), especially its Volume Viewer plug-in (Barthel, 2005), was also used to capture shots of structures, notably ameloblasts, and reposition the stacks in the $(x y)$ plane to facilitate segmentation. Finally, Simulenam virtual $3 \mathrm{D}$ models were constructed on the basis of the
3D segmentation of the observed prisms (see also AlloingSéguier et al., 2017).

The 2D enamel samples were prepared following the same protocol as Alloing-Séguier et al. (2014). Vertical, horizontal, and tangential slices were performed to obtain complementary section planes, and microstructure was then observed with a scanning electron microscope (SEM).

\section{RESULTS AND DISCUSSION \\ Methodology}

Samples cut in the frontal plane reacted less favorably to the sectioning and staining protocols than those cut in the sagittal plane. This could be explained by the fact that a frontal section of an isolated incisor represents less material than a sagittal one, which includes the full length of the incisor, and this could impact the integrity of the demineralized enamel. The optimal concentrations of staining agents were also gradually optimized. It is worth noting that the precise mechanism of the molecular staining of enamel was uncertain at first, although as demonstrated by Kwon et al. (2012) rhodamine can penetrate enamel deeply even without demineralization, so it is probable that our staining simply diffuses through enamel. This interpretation is supported by the fact that prisms are best distinguished with a TRITC staining rather than with a phalloidin-TRITC one (used for staining cellular membranes), thereby suggesting that the size of the staining agent influences the staining's quality (a smaller agent diffusing more easily). Comparison between confocal and SEM observations for Mus musculus validates the confocal methodology used (Fig. 2).

It was noted that all enamel types are not equally suitable for observation and reconstruction. Uniserial decussated enamel (Mus musculus) is particularly appropriate for reconstruction, thanks to the marked difference in prism orientation between adjacent rows, as it is easier to distinguish a prism from its close neighbors when their $3 \mathrm{D}$ trajectory is not the same. Reconstruction is more complicated for multiserial decussation (Myocastor
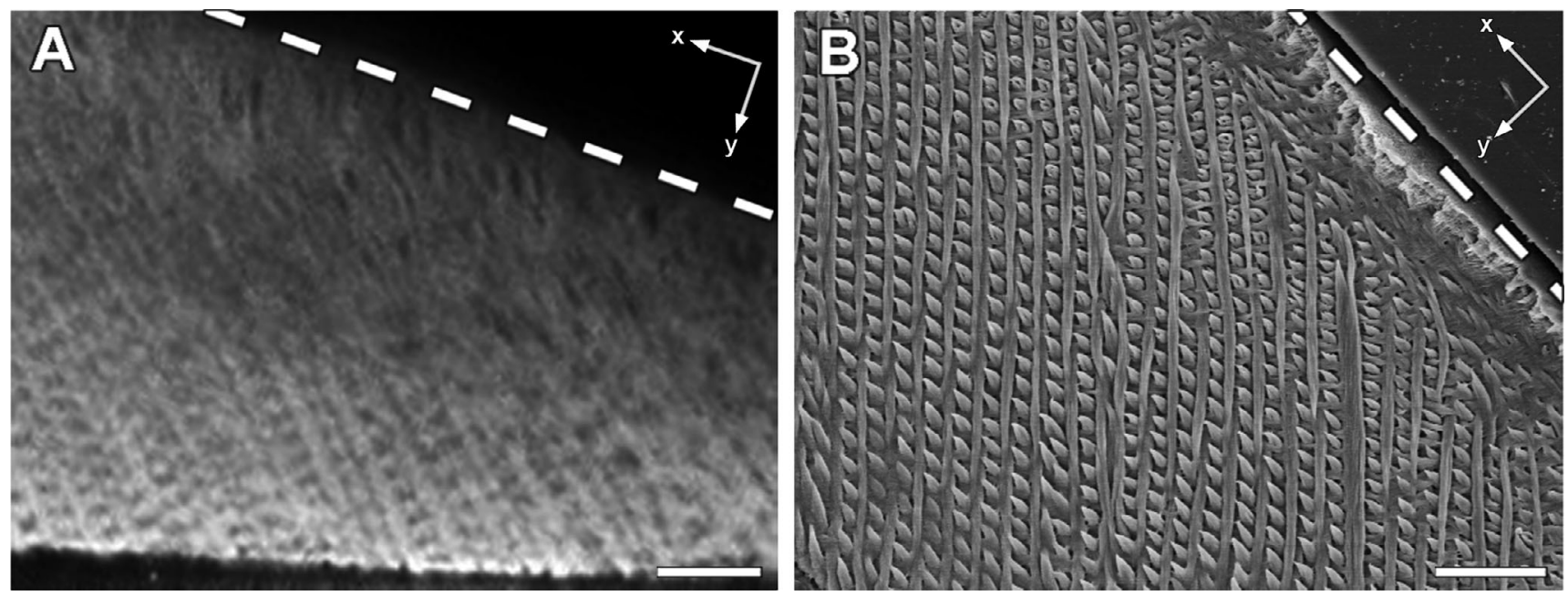

Fig. 2. Comparison between a virtual sagittal slice from the confocal microscopy 3D data of a Mus musculus lower incisor performed with the Fiji Software (A) and a sagittal slice of a Mus musculus lower incisor observed with SEM (B). The uniserial decussation pattern is clearly visible on both slices. OES is represented as a dashed line. Scale bars: $25 \mu \mathrm{m}$. 

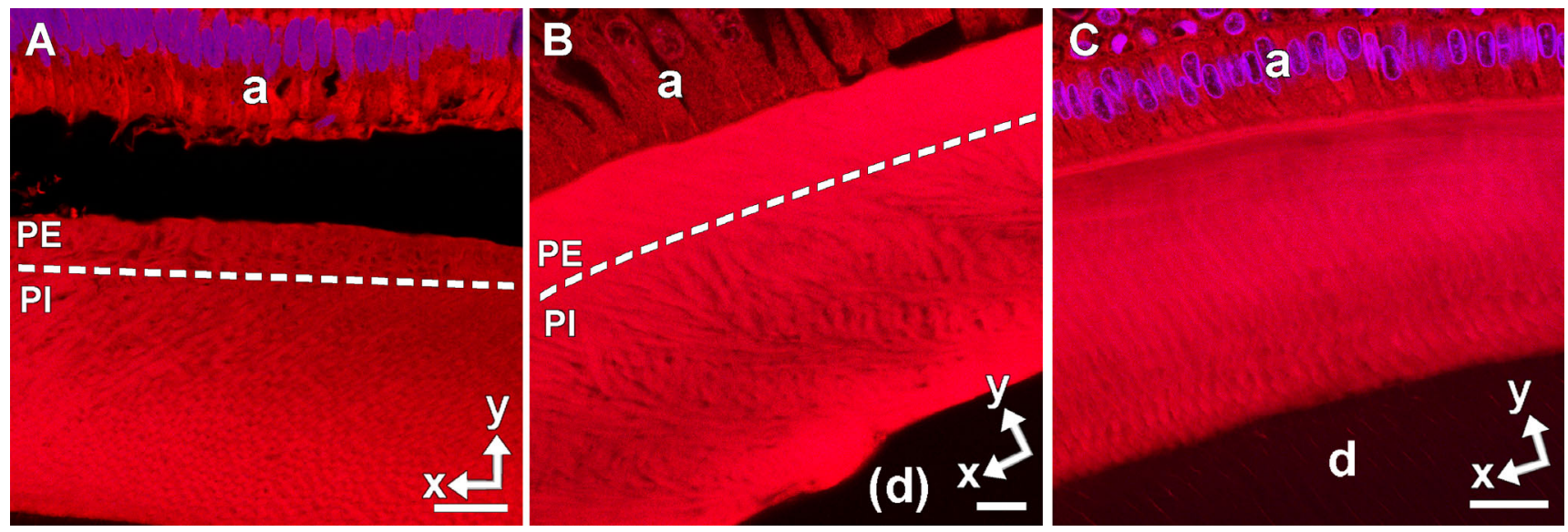

Fig. 3. Stained sagittal slices observed with confocal laser microscopy and used for segmentation. The enamel layer is located between the dentine (d) and the ameloblast layer (a). (A) Mus musculus; ameloblasts dissociated from the enamel during sectioning, leaving a small space between them (scale bar: $25 \mu \mathrm{m}$ ). (B) Myocastor coypus; the dentine dissociated from the enamel during sectioning and was lost (scale bar: $10 \mu \mathrm{m}$ ). (C) Didelphis marsupialis (scale bar: $25 \mu \mathrm{m}$ ). PI: portio interna; PE: portio externa.

coypus), because it can be difficult to isolate accurately the boundaries of a single prism when other prisms of the same orientation type surround it. As for radial enamel (Didelphis marsupialis), even if the prism-to-prism distance is reasonably sufficient to lessen the risk of mixing them up, it is not always possible to follow the same prism from beginning to end, being sometimes indistinguishable from the IPM, especially near the OES (this could thus result from a mineralization differential). In rodent incisors, the prisms in the portio externa (also radial enamel) share the same problem. Finally, a newly secreted, usually thin enamel layer rarely allows reconstruction of prisms at all, as this enamel is stained indiscriminately, and the occasional piece of prism cannot be followed for more than $5 \mu \mathrm{m}$. This is likely due to the newly secreted enamel being insufficiently mineralized. Indeed, in rodents, it is mainly during the maturation phase, after the end of secretion, that prisms gain in width and definition (Nylen et al., 1963).

Concerning ameloblasts, the entire volume of the cells was not equally stained, which has impacted our capacity to observe and reconstruct them. While the nucleus is always apparent (DAPI staining), both the cytoplasm and cytoplasmic membrane often appear mottled and not well defined, except in a zone close to the apical pole of the cell, here termed the "apical level" (Fig. 1B). For this reason, our investigation of ameloblast morphology and organization focused on the specifically stained and distinctive apical level. Moreover, visualizing ameloblasts in cross-section usually requires geometric transformations of the confocal images, which has a negative impact on resolution and on the fidelity of $3 \mathrm{D}$ segmentation as a result. We were still able to determine that ameloblast diameter varies along the long axis of the cell, being largest in the nucleus and apical levels, and usually reduced between these two zones, which can involve a slight gap between adjoining cells. Some of the limitations of this methodology regarding visualization and reconstruction of enamel could be addressed by improving the protocol of confocal microscopy acquisitions. Shortening the step between each frame (from $0.21 \mu \mathrm{m}$ to $0.13 \mu \mathrm{m})$ and increasing the averaging of each individual frame (from 3 to 8 replications of the same frame) already proved effective for enhancing acquisition quality and thus reconstruction, but these more efficient parameters induce a longer, impractical acquisition time (from two to more than $8 \mathrm{hr}$ per acquisition).

\section{Observations and Measurements}

The enamel thickness of Mus musculus comprises two zones (Fig. 3A), one with radial enamel, the portio externa (close to the OES), and one with uniserial decussation, the portio interna (close to the EDJ), as described by Korvenkontio (1934), where the two orientation types diverge by $59^{\circ}$ (Standard Deviation $=6.06$ ). Rows of prisms in the decussated zone are not perfectly straight, even slightly undulated at times, and form an angle of approximately $35^{\circ}$ with the EDJ surface. The respective orientations of each row remain mostly constant from the EDJ to the radial zone (Fig. 4A). These observations are congruent with those made with SEM for Mus musculus, and with the reconstructed $3 \mathrm{D}$ prisms of rat enamel, which share the same microstructure type (Warshawsky and Smith, 1971). Prisms are $2.03 \mu \mathrm{m}$ wide in average $(\mathrm{SD}=0.33$ ), with a calculated mean perimeter of $6.37 \mu \mathrm{m}$. Prisms of the same row are separated by $2.01 \mu \mathrm{m}$ of IPM on average $(\mathrm{SD}=0.66)$, and prisms of different rows by $4.49 \mu \mathrm{m}$ on average $(\mathrm{SD}=0.78)$.

At the beginning of secretion for Mus musculus, the ameloblasts generating the portio interna have a mean maximal diameter of $2.34 \mu \mathrm{m}(\mathrm{SD}=0.40)$ at the apical level, with a mean perimeter estimated at $7.02 \mu \mathrm{m}$ for a hexagonal cell. Ameloblasts are organized in an "alternate" pattern: a repetitive disposition of elements organized in rows, where one row out of two is offset by half an element's length with respect to the previous and next rows. Same-row cells are adjoined near their apical pole, and separated from other rows by $1.09 \mu \mathrm{m}$ on average $(\mathrm{SD}=0.39)$. At the end of enamel secretion (Fig. $5 \mathrm{~A})$, the ameloblasts have a mean maximal diameter of $6.52 \mu \mathrm{m}$ $(\mathrm{SD}=2.52)$ and calculated mean perimeter of $19.55 \mu \mathrm{m}$. They are still organized in an alternate pattern with same-row cells adjoined near the apical pole, but are now separated from the next rows by $5.08 \mu \mathrm{m}$ on average 
$(\mathrm{SD}=2.74)$. Ameloblasts seem to be organized more evenly near the basal pole.

The enamel thickness of Myocastor coypus is also divided into a portio externa (radial zone) and a portio interna (decussated zone), although in this case the decussation is multiserial: prisms are organized in bands of two alternating orientation types, five prisms per band on average, with individual prisms and rows of the same orientation sometimes difficult to distinguish among each other (Fig. 3B). Rows form a mean angle of $19.7^{\circ}$ with the EDJ surface (SD $=4.3$ ). Some prisms, located at the junction of two bands, display an orientation that is different from the two main orientation types and instead appears intermediate (represented in magenta on Fig.4B). This could correspond to transitional prisms, as described for 2D data (Martin, 1993). The two orientation types form an angle of approximately $90^{\circ}$ in the portio interna, but at the shift to the portio externa, one orientation slightly changes its course, while the other experiences a sharp turn at $90^{\circ}$ (Fig. 4B). Prisms are $1.48 \mu \mathrm{m}$ wide in average $(\mathrm{SD}=0.19)$, with a calculated mean perimeter of $4.64 \mu \mathrm{m}$. They are separated from each other by $0.35 \mu \mathrm{m}$ of IPM on average $(\mathrm{SD}=0.44)$.

At the beginning of secretion, the ameloblasts of $M y^{\circ}$ castor coypus have a mean maximal diameter of $2.64 \mu \mathrm{m}$ $(\mathrm{SD}=0.35)$ at the apical level, with an estimated mean perimeter of $8.29 \mu \mathrm{m}$ (Fig. 5C). Cells seem to be organized in an alternate pattern, although on a larger scale they appear to form islets of cells separated from each other by $8.00 \mu \mathrm{m}$ on average (SD $=3.50$; Fig. $5 \mathrm{D})$. In one such islet, cell apices are separated by $1.58 \mu \mathrm{m}$ on average $(\mathrm{SD}=0.82)$. At the end of secretion, the ameloblasts have a mean maximal diameter of $5.69 \mu \mathrm{m}(\mathrm{SD}=1.08)$, and an estimated mean perimeter of $17.06 \mu \mathrm{m}$. Cell apices are in direct contact with each other, thus reinforcing the hexagonal shape in apical view, and each one is typically adjoined to six other cells. They are organized in an alternate pattern (Fig. 5D).

The enamel of Didelphis marsupialis is uniform. All prisms share the same orientation, making them sometimes hard to distinguish among themselves, especially near the OES (Figs. 3C and 4C), although there are one or two instances of synchronous changes in this shared orientation-one at the first third of the enamel thickness, close to the EDJ, with prisms all bending in the $(y z)$ plane, and possibly another, in the last third of the thickness, close to the OES, in the $(x y)$ plane. Prisms are $2.60 \mu \mathrm{m}$ wide on average $(\mathrm{SD}=0.53)$, with an estimated mean perimeter of $8.16 \mu \mathrm{m}$, and are separated from each other by $2.77 \mu \mathrm{m}$ of IPM on average $(\mathrm{SD}=0.55)$. In one case, a prism has been observed as beginning its course well after the EDJ (represented in cyan on Fig. 4C), growing spontaneously between two previously contiguous prisms; the new prism and its neighbors are separated by the usual amount of IPM once the former reaches its full diameter.

At the beginning of secretion, the ameloblasts of Didelphis marsupialis have a mean maximal diameter of $4.25 \mu \mathrm{m}(\mathrm{SD}=0.64)$ at the apical level, with a calculated mean perimeter of $12.76 \mu \mathrm{m}$. Cells are organized in an alternate pattern and are adjoined to each other. At the end of secretion, the ameloblasts have a mean diameter of $3.78 \mu \mathrm{m}(\mathrm{SD}=1.18)$ and a mean perimeter estimated at $11.34 \mu \mathrm{m}$ (Fig. 5B). Cell apices are separated from each other by $2.53 \mu \mathrm{m}$ on average $(\mathrm{SD}=0.75)$ and still organized in an alternate pattern.
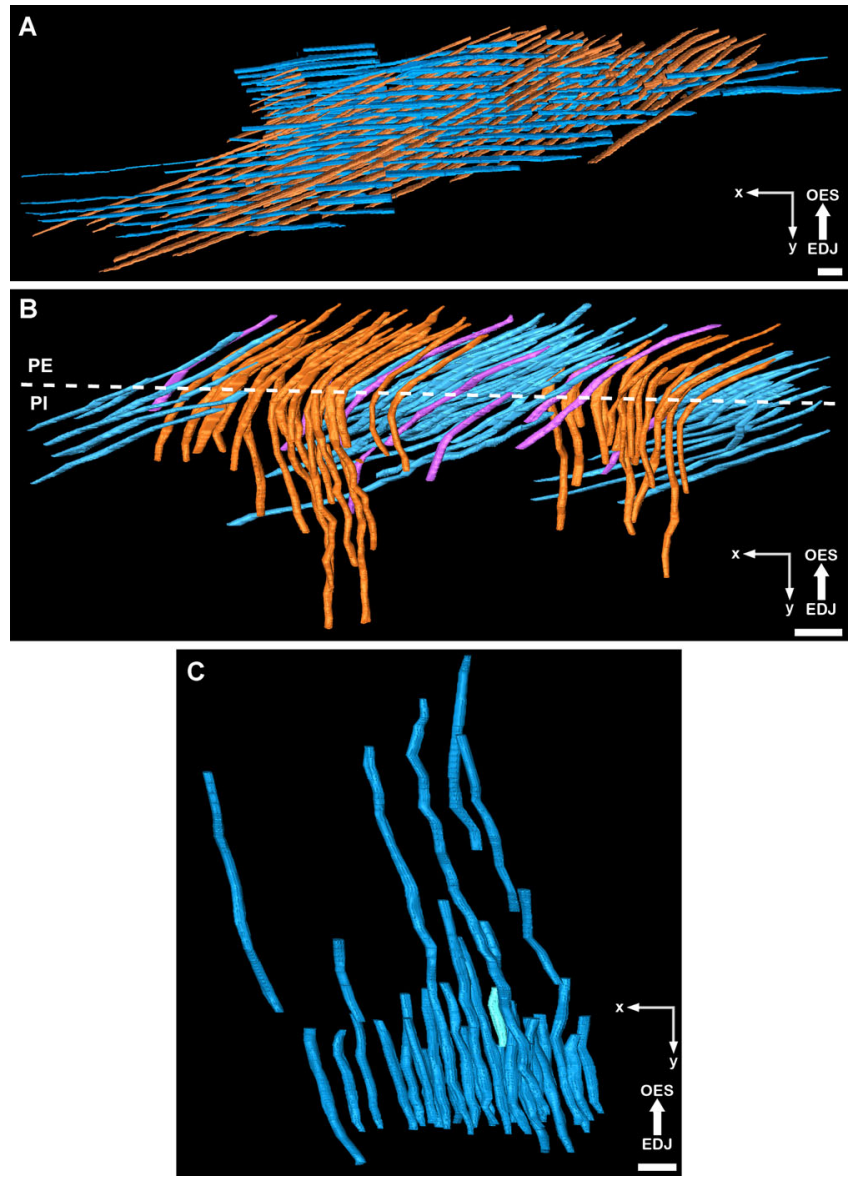

Fig. 4. 3D prisms segmented with the Avizo software. The different orientation types are figured in blue and in orange, while potential transition prisms are in magenta. (A) Mus musculus, portio interna only; (B) Myocastor coypus, from EDJ to OES, portio interna and portio externa; (C) Didelphis marsupialis, from EDJ to OES, with one prism starting beyond the EDJ in cyan. Scale bars: $10 \mu \mathrm{m}$.

\section{Simulenam Reconstructions}

Simulenam is a software dedicated to the $3 \mathrm{D}$ virtual reconstruction of enamel microstructure (Alloing-Séguier et al., 2017). In a $(x, y, z)$ coordinate system, a virtual prism is generated along the $\mathrm{y}$ axis, with a set of parameters affecting its course on the $x$ and $z$ axes. This individual prism can then be duplicated to fill out the allocated virtual volume, with additional parameters to determine the way these prisms are organized among each other. Notably, it is possible to arrange prisms in two sets of alternating rows, each with specific $x$ axis parameters. Finally, once the desired three-dimensional volume of virtual prisms has been created, it is possible to configure a section plane to produce a two-dimensional view of the prisms' cross-section. A visual representation of the Simulenam parameters most relevant to the present study can be found in Supporting Information; for a complete list of the parameters that can be used in Simulenam, see Supporting Information of Alloing-Séguier et al. (2017).

On the basis of the segmented prisms, it is possible to simulate the microstructure of Mus musculus, Myocastor coypus, and Didelphis marsupialis. For the two rodent 

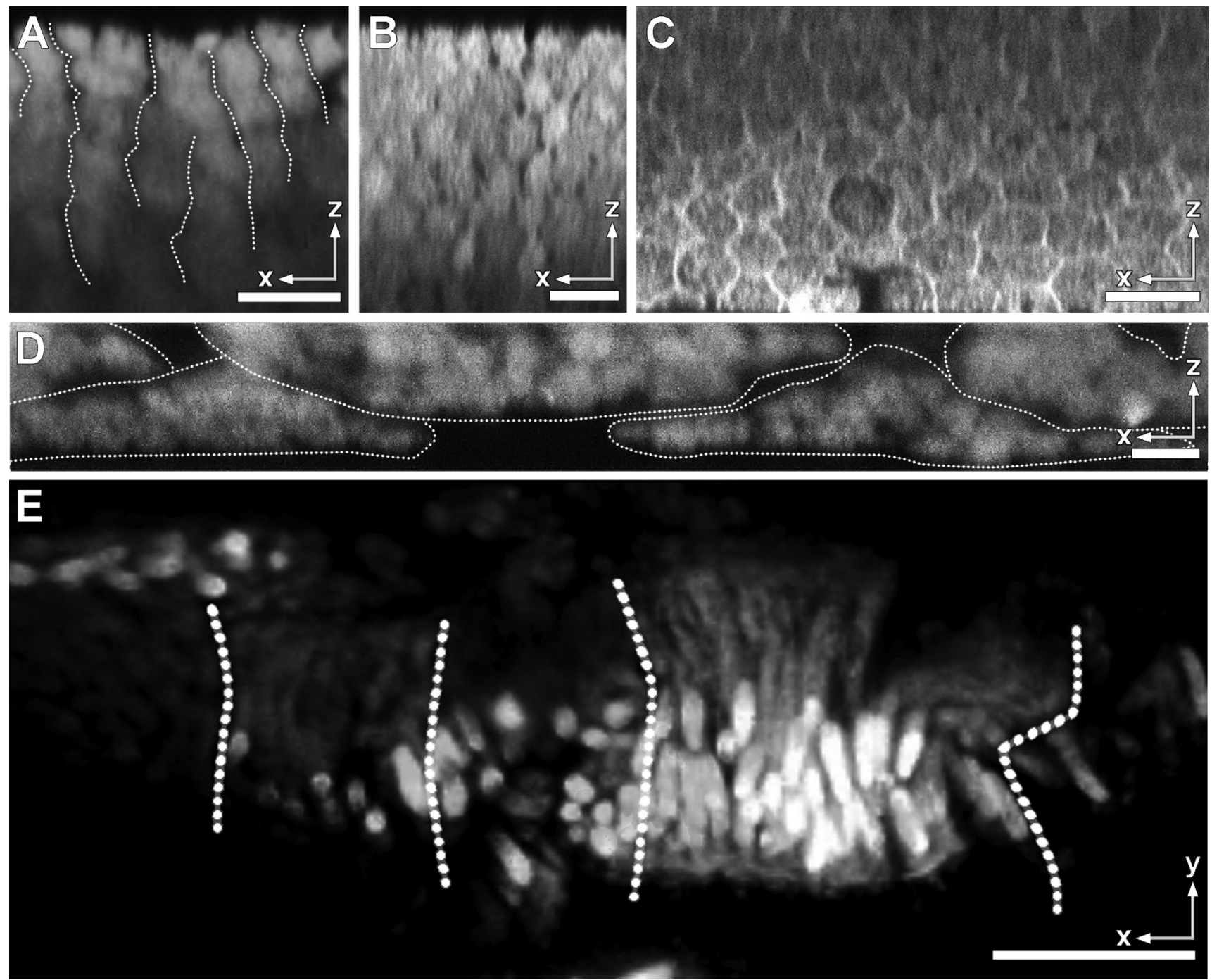

Fig. 5. Virtual slices of confocal 3D data performed at the apical level of ameloblasts, viewed in ImageJ. (A) Mus musculus, end of secretion, with dotted lines indicating potential band delimitations (scale bar: $20 \mu \mathrm{m}$ ); (B) Didelphis marsupialis, end of secretion (scale bar: $10 \mu \mathrm{m}$ ); (C) Myocastor coypus, end of secretion (scale bar: $10 \mu \mathrm{m}$ ); (D) Myocastor coypus, during secretion of the portio interna, with dotted lines indicating potential islet delimitations (scale bar: $20 \mu \mathrm{m}$ ); (E) Myocastor coypus, lateral view during secretion of the portio interna, with dotted lines indicating potential islet delimitations (scale bar: $25 \mu \mathrm{m}$ ).

incisors, which exhibit an enamel with a decussated portio interna, prisms adopt one of two different orientation types, and do not change orientation until they uniformly and synchronously adopt a third orientation type, forming radial enamel. This kind of microstructure, with prisms of the decussated portion that are rectilinear and do not change orientation during amelogenesis until the shift into radial enamel, is coherent with a crossing model of decussation, and can be reconstructed with Simulenam.

The main difference between Mus musculus (Fig. 6A) and Myocastor coypus (Fig. 6B) is the number of contiguous rows of prisms sharing the same orientation-one row for the former, five rows in average for the latter. This is represented in Simulenam by the parameters "Interlacing" (presence or absence of interlacing bands of prisms) and "Interlacing density" (number of prisms per interlacing band). The two orientation types of the portio interna are controlled independently through the "Prism Main Plane" and "Interlaced Main Plane" sets of parameters. The near-orthogonal angle of decussation observed for the multiserial decussation type can be simulated by setting the values of the main angle of "Prism Main Plane" and of "Interlaced Main Plane" at $-45^{\circ}$ and $+45^{\circ}$ with respect to the virtual Horizontal/frontal surface $(y z$ plane). For the uniserial type, they are closer to $-30^{\circ}$ and $+30^{\circ}$. The prisms are more closely packed intra-row ("Prism z spacing") than inter-row ("Prism y spacing"), almost touching, leaving only enough space for the IPM to adopt a plate-like aspect. However, the shape of the prisms (oval for Mus musculus and Myocastor coypus, round for Didelphis marsupialis) is not yet configurable in Simulenam and is defaulted as round. The radial portion of Mus musculus is simulated as swerving sharply along the $x$ axis ("Prism Secondary Plane" set of 
A

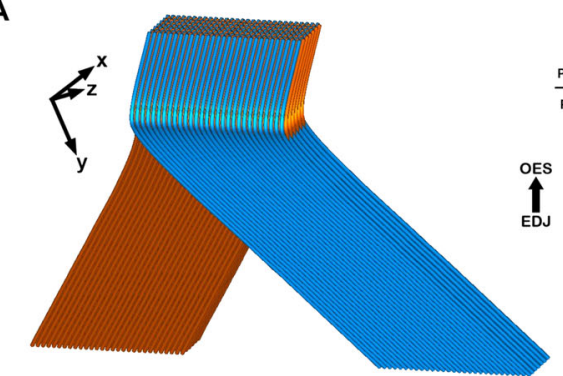

B

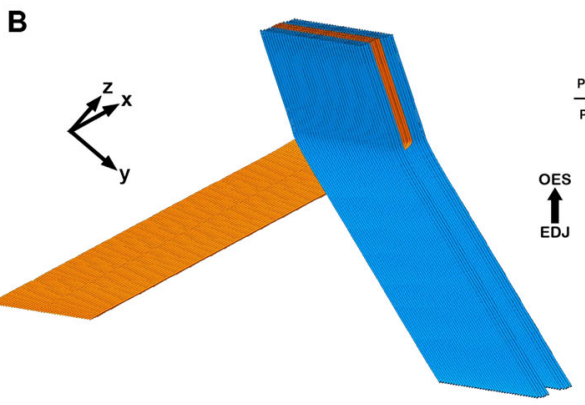

C

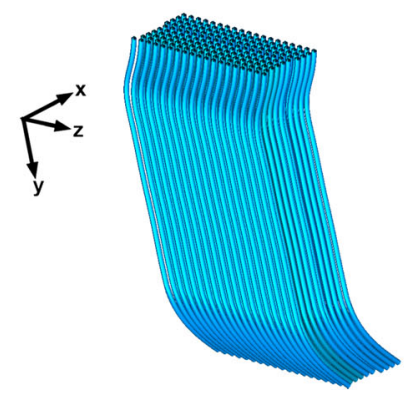

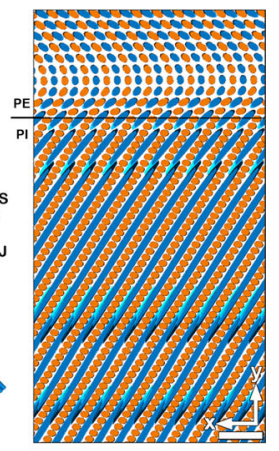
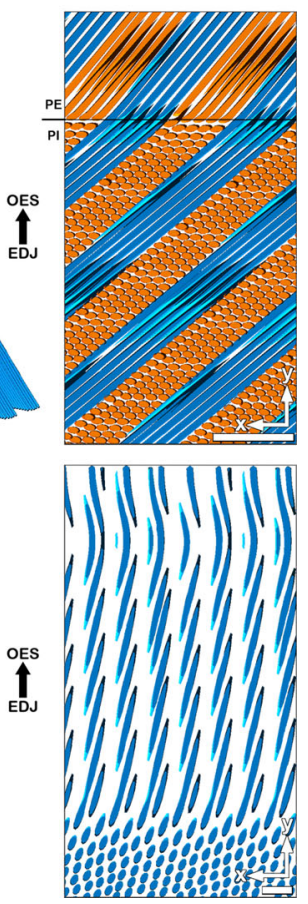

Fig. 6. Simulenam reconstructions. Full 3D simulation at left, and full 2D cut of the corresponding 3D simulation at right (portio interna/PI in the lower $75 \%$, portio externa/PE in the upper $25 \%$ ); each full simulation is an assemblage of multiple single simulations. The white space between prisms would stand for the IPM. (A) Mus musculus; (B) Myocastor coypus; (C) Didelphis marsupialis. Scale bars: $10 \mu \mathrm{m}$.

parameters) from the decussated portion, while the orientation of prisms in the radial portion of Myocastor coypus is reconstructed as only slightly diverging from one of the portio interna orientation types. As for the radial enamel of Didelphis marsupialis (Fig. 6C), prisms are more widely and uniformly spaced, and this prism arrangement is simulated without the "Interlacing" parameter, only the "Prism Main Plane" and "Prism Secondary Plane" sets.

\section{Relationship Between Prisms and Ameloblasts}

The space between the supra-nuclear parts of neighboring ameloblasts, which can be less closely packed near the apical pole, varies according to cell organization. For Mus musculus, same-row cells are closer to themselves than to cells of other rows, even adjoined in some cases (Fig. 5A). As for Didelphis marsupialis (Fig. 5B),

ameloblasts at the end of secretion are widely spaced (mean distance of $2.5 \mu \mathrm{m}$ for cells of $3.8 \mu \mathrm{m}$ of average diameter), with cellular extensions or "bridges" linking them together-potentially representing desmosomes, which are supposed to control epithelial cohesiveness (Kitajima, 2002; Nekrasova and Green, 2013). Lastly, as described above, ameloblasts can also be entirely adjoined to each other (Myocastor coypus at the end of secretion, and Didelphis marsupialis at the beginning of secretion).

The mean width of an ameloblast is variable across taxa, as well as from one stage of secretion to the other for each taxon. For Mus musculus, the cell diameter doubles between the beginning and the end of secretion, and space between rows also increases notably at the apex (Fig. 7A,B). This observation is congruent with those performed on the rat by Smith and Warshawsky (1977), who proposed that ameloblasts progressively enlarge to compensate for the surface increase of the secreted enamel. Apoptosis of some ameloblasts at the beginning of the maturation phase (Smith and Warshawsky, 1977) could also have an effect on the cell-to-cell distance in the ameloblast layer. For Myocastor coypus, the diameter of cells also increases along the secretory phase, but in this case, the space between cell apices diminishes until they end up adjoined at the end of secretion (Fig. 7C,D). Conversely, for Didelphis marsupialis, cell apices at the beginning of secretion are adjoined, and are widely spaced at the end (Fig. 7E,F). As the difference in diameter between the beginning and the end of secretion cells is minor, it is possible that the ameloblast expansion mechanism in rodents does not exist in Didelphis marsupialis. Another pattern of compensation of the increase of the surface of enamel might be expected in this case, like the formation of cytoplasmic expansion keeping cells together.

Comparing size and organization of ameloblasts and prisms reveal a clear disparity between taxa. For Mus musculus, the row pattern is discernible with both prisms and cells (the row patterning of mouse ameloblasts is well represented on video S28 in Smith et al., 2016). Although ameloblasts at the end of secretion are at least three times larger than prisms, they are of equivalent diameter at the beginning of secretion. At the end of secretion, the space between cell apices is greater than the space between prisms, and vice versa at the beginning. For Myocastor coypus, there is a difference between prism and ameloblast size. At the beginning as well as the end of secretion, cells are quite larger than prisms-by a factor of two then five, respectively. This difference casts some doubts on the "one prism/one ameloblast" hypothesis (Boyde, 1964, 1967; Osborn, 1970a), which still seemed to be supported for the rat as one prism/one Tomes' process (Kallenbach, 1973). Examining the shape of Tomes' processes of Myocastor coypus would be enlightening, but could not be managed here with enough precision; potential traces of Tomes' processes could be represented by the "frayed" OES surface of developing enamel observed in some of our sample, but they are too faint for accurate segmentation. It is possible that the process of a single ameloblast could subdivide itself into various secretory zones rather than only one, or that a single ameloblast could possess multiple processes at the same time. As for the organization of the cells, they begin secretion some distance between their apices, to end adjoined as larger hexagons. There is no specific link to prism organization, 
A

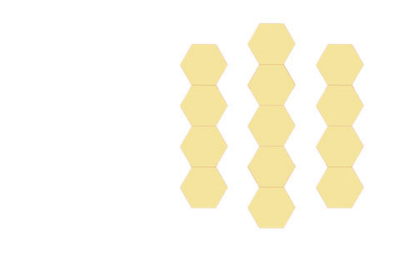

C
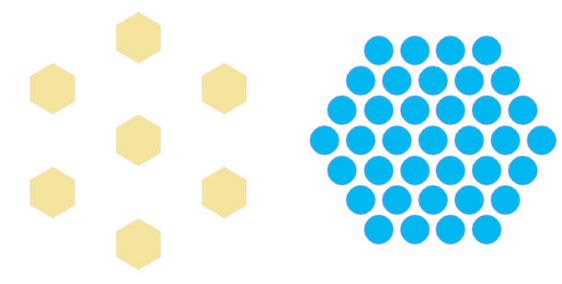

E
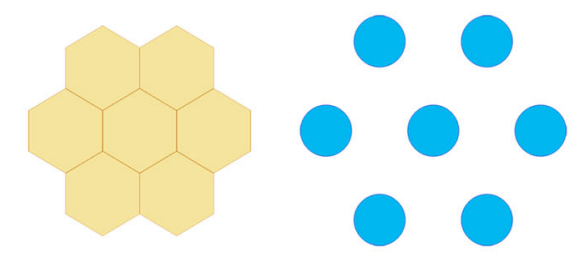

B
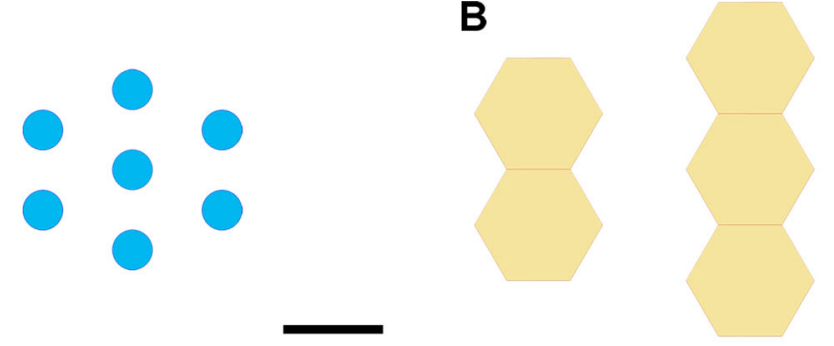

D
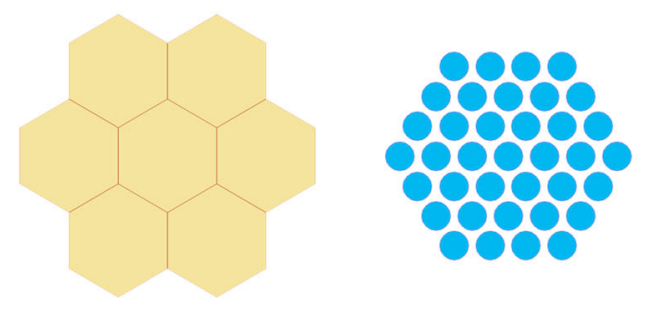

$\mathbf{F}$

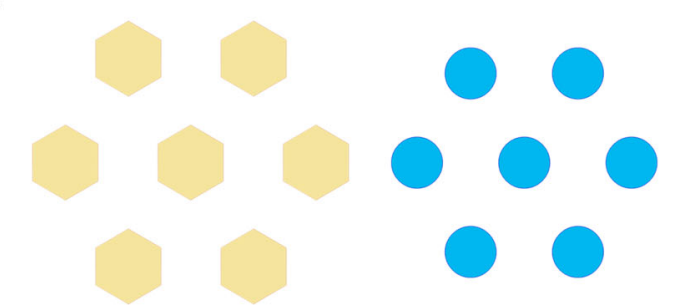

Fig. 7. Schematic representation of the size and organization relationship between ameloblasts (yellow), as measured at the apical level, and prisms (blue) of the same specimen (scale bar: $5 \mu \mathrm{m}$ ). (A) Mus musculus, during secretion of the portio interna; (B) M. musculus, after the end of secretion; (C) Myocastor coypus, during secretion of the portio interna; (D) M. coypus, after the end of secretion; (E) Didelphis marsupialis, during secretion; (F) Didelphis marsupialis, after the end of secretion.

except for the presence of cell islets at the beginning of secretion, a point discussed below. For Didelphis marsupialis, the size of the ameloblasts is of the same order of magnitude as the size of the prisms, being only slightly larger, both at beginning and end of secretion. Even if cells at the beginning are adjoined and become quite spaced at the end, their organization does not conflict with the prisms arrangement. In this case, the cell-prism relationship seems to be direct.

There is no generation of new ameloblasts after the onset of the secretion phase (Smith and Warshawsky, 1977). However, the progressive change of some of the ameloblasts observed by these authors, with an apically positioned nucleus migrating to a basal position, could imply that all ameloblasts are not necessarily active at the beginning of secretion. Some would initiate their secretory activity later, the migration of the nucleus allowing the setting up of the specific morphology of the Golgi apparatus and the endoplasmic reticulum. This would also entail an increase in produced enamel, coherent with the gradual enlargement of the secretion front, and the formation of prisms that did not begin at the EDJ. This last point is directly confirmed by the segmentation of a prism in the enamel of Didelphis marsupialis that unambiguously begins its course more than $20 \mu \mathrm{m}$ after the EDJ (represented in cyan on Fig. 4C). Associated with possible organization changes in the ameloblast layer, this could help explain one of the results of Tafforeau et al. (2012), where prisms segmented from the EDJ to the OES grew apart from each other, with the possibility of other prisms inserting between them. In fact, it had already been demonstrated that the number of prisms reaching the OES could be larger than the number of prisms starting at the EDJ (Fosse, 1968).

\section{Formation of Decussation}

As previously suggested (Boyde, 1964, 1997; Smith and Warshawsky, 1975, 1977), the organization of ameloblasts in rows seems to be linked to the arrangement of prisms, which is especially apparent for the uniserial decussation of Mus musculus. The sliding of rows is among the most parsimonious mechanisms for explaining the formation of prisms crossing each other in the enamel thickness. Indeed, in the case of Mus musculus, for example, two prisms of differing orientation, starting side-byside at the EDJ, end up widely spaced when they reach the limit of the portio interna. This implies that the two associated ameloblasts were in close proximity at the beginning of the secretory phase and finished far apart at the end. The multiserial decussation of Myocastor coypus could be interpreted as a variation on the same basic mechanism of the uniserial type, with multiple contiguous rows sliding together in the same direction instead of 
A

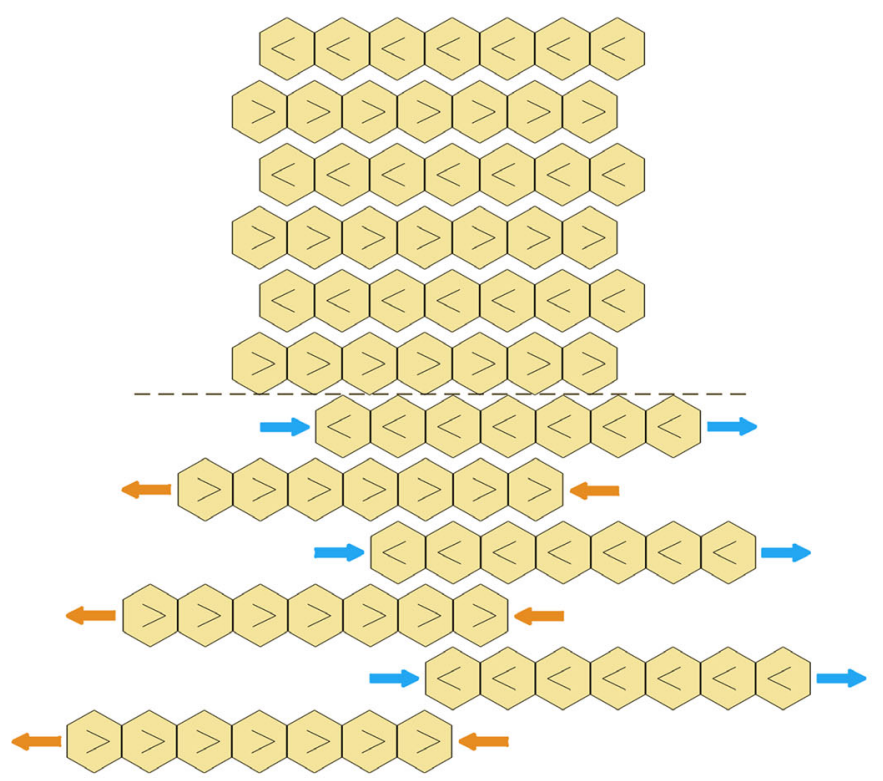

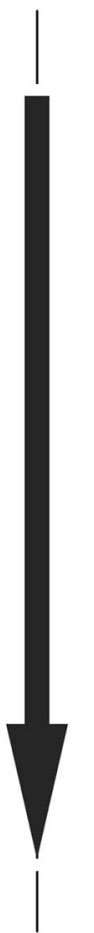

B

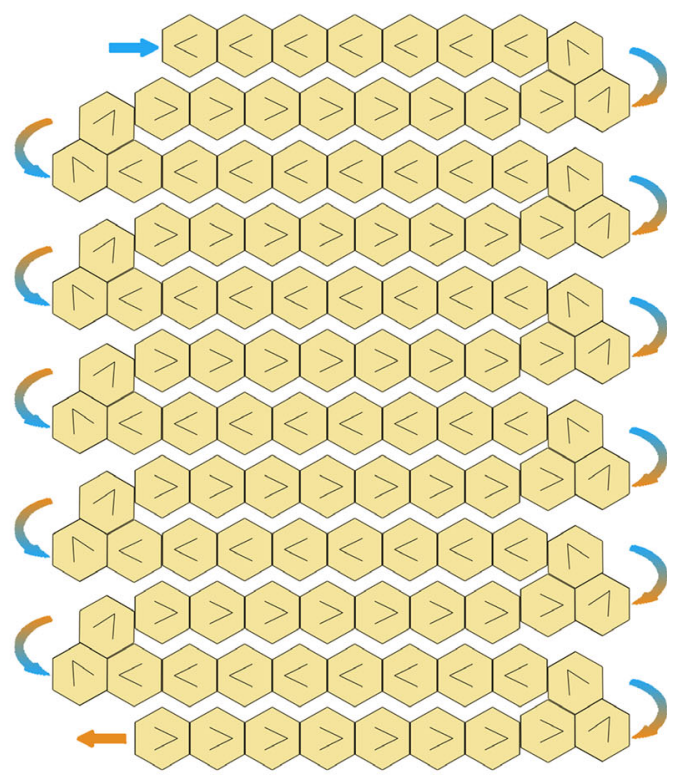

Fig. 8. Schematic representation of the sliding of ameloblast rows in tangential view. Ameloblasts (in yellow, with putative orientation of the Tomes' process) are organized in single-cell rows, as for a uniserial decussation type. The epithelium migrates toward the distal tip of the incisor (black arrow), and rows slide against each other (colored arrows, blue for one orientation type, orange for the other). (A) Epithelium without mechanism to preserve its integrity, sliding of rows debuting below the dashed line; (B) Epithelium with the proposed mechanism of integrity preservation, with the cell of a given row reaching the lateral limits of the epithelium being recruited by the following row.

each row individually. This suggestion is supported by the observation of ameloblast islets or clusters of rows in apical and vertical views (Fig. 5D,E) that would slide among each other in the same way as the individual rows of the uniserial type. According to the size difference between prisms and ameloblasts, only three or four rows of cells per islet, producing same-orientation prisms, would be sufficient to generate a complete band. Transitional prisms could be explained as intermediate rows or cells between islets, or as ameloblasts migrating from one islet to the other. Finally, the radial enamel of Didelphis marsupialis corresponds to a homogeneous organization of ameloblasts, without any sliding among themselves. These observations are all congruent with a crossing model of decussation.

This decussation mechanism is expected to be discernible at the level of cellular junctions, including desmosomes (Nekrasova and Green, 2013), tight junctions (Runkle and $\mathrm{Mu}, 2013$ ), and gap junctions (Hervé and Derangeon, 2013), as well as actin microfilaments (Gardel et al., 2010). As it is, the apical and basal poles of an ameloblast are entirely surrounded by junctional complexes (Warshawsky, 1978), which are more extensive at the basal pole (mainly desmosomes) than at the apical one (some desmosomes, but predominantly tight junctions). Furthermore, at the apical pole, gap junctions are larger between ameloblasts of the same row, while tight junction are more developed and desmosomes more numerous between ameloblasts of two different rows. As for microfilaments, their distribution and number are different between the two situations-intra- or inter-row (Kallenbach, 1973; Warshawsky, 1978; Nishikawa et al., 1988). This peculiar distribution of junctional complexes has been proposed to be implicated in the sliding of rows between each other, which is furthered by the observation that this organization is modified when ameloblasts start secreting radial enamel, especially for microfilaments (Kallenbach, 1963, 1973; Nishikawa et al., 1988; Yuan and Nishikawa, 2014; Nishikawa, 2017). Cells of the Stratum Intermedium, the tissue lying against the basal pole of ameloblasts, could also have a role in the coordination of ameloblast function and migration (Lesot et al., 2014).

A practical pitfall of an organization into sliding rows concerns the lateral extremities of the epithelium. Indeed, as ameloblasts migrate toward the distal tip of the growing incisor, they are also subjected to the transverse sliding of rows, which carries them progressively to the lateral borders of the secreted enamel. However, without generation of new ameloblasts during the secretory phase, the growing offset between rows of differing orientation would cause the epithelium to literally pull itself apart (Fig. 8A). As the number of ameloblasts is stable during the secretion phase (Smith and Warshawsky, 1977), and their only zone of proliferation is located at the base of the incisor, it suggests that there is a mechanism to counteract the increasing offset between rows of ameloblasts. We propose that the lateral-most ameloblast of a row, which is pushed toward the extremity of the epithelium, could latch onto the trailing ameloblast of a contiguous row sliding in the opposite direction. Cells would not migrate sideways ad infinitum, and would fill the gaps left at the trailing ends of rows, maintaining the integrity of the epithelium. Under this hypothesis, 

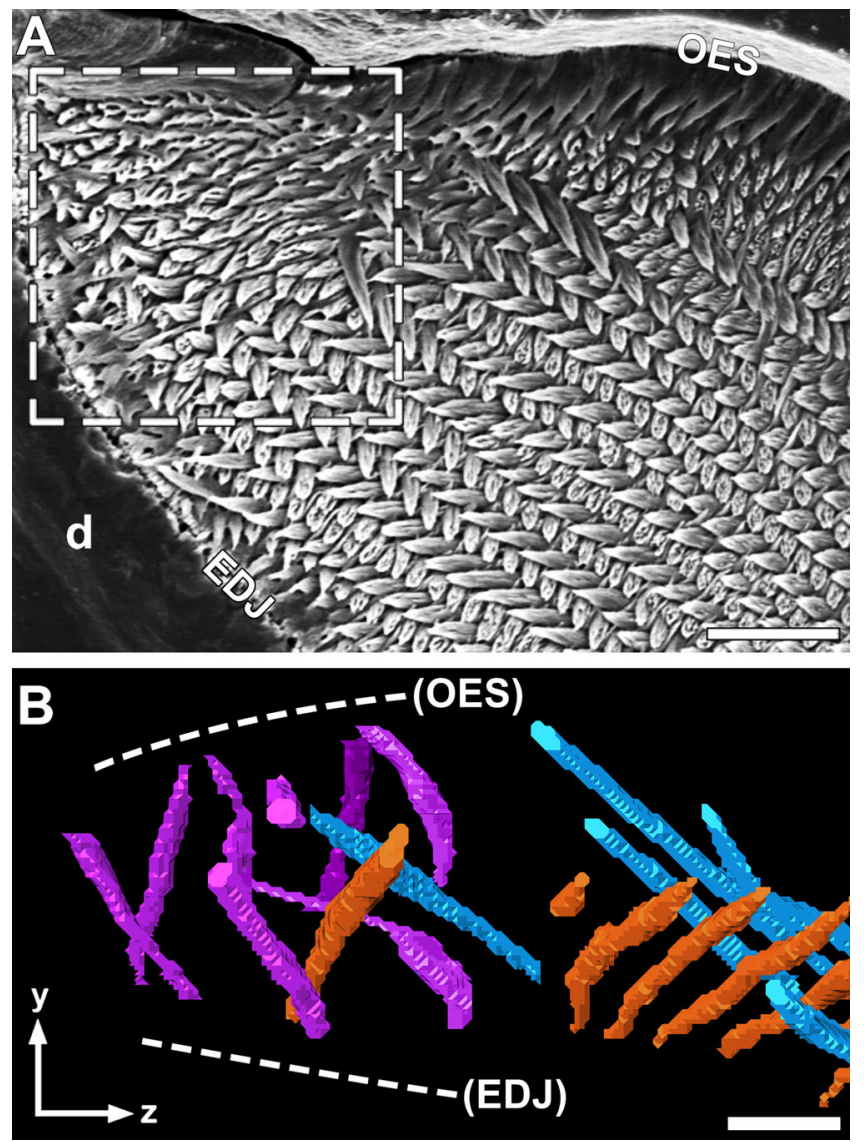

Fig. 9. Peculiar pattern of prisms at the lateral extremities of the ename layer. (A) Frontal section of a lower incisor of Mus musculus (SEM) showing uniserial decussation type in the portio interna and radial ename in the portio externa. The zone delimited by the dashed square displays a degradation of the uniserial pattern, with some prisms adopting eccentric orientations (d: dentine; scale bar: $15 \mu \mathrm{m}$ ). (B) Segmentation of the relevant zone of confocal microscopy 3D data with the Avizo software, with prisms of usual orientation types in blue and orange, and prisms of eccentric orientation in magenta (scale bar: $10 \mu \mathrm{m}$ ).

the ameloblast layer would operate like a horizontal, folded conveyor belt (Fig. 8B), thereby allowing the lateral sliding of cells or islets of cells and apparent rows, while maintaining the layer's integrity. This mechanism would impact prism orientation in the folding zones located at the lateral peripheries of the epithelium, if ameloblasts keep secreting enamel as they switch from one row to another. This is actually apparent both in SEM images and for segmented prisms, with prisms in these zones losing the regularity of the decussation pattern and adopting intermediate or eccentric orientations (Fig. 9).

\section{Evolution of Decussation Parameters}

Extinct and extant rodent enamel microstructure has been extensively studied (e.g., Korvenkontio, 1934; Martin, 1993, 1994, 1999, 2007; Kalthoff, 2000; Koenigswald, 2004; Marivaux et al., 2004), providing a thorough picture of how its various characters evolved through time. The fossil record can thus act as a powerful framework to further explore the mechanisms of microstructure formation, especially decussation.

Decussation in rodents first developed, from radial enamel, as the pauciserial type (Martin, 1993). It is characterized by a portio interna with a weak angle of decussation, bands of usually three to six prisms with a round cross-section, and a thick IPM sheath surrounding the prisms. In the portio externa, prisms are moderately inclined relative to the OES. The pauciserial type is characteristic of the oldest known rodents (Martin, 1993, 1997; Marivaux et al., 2004), but it diversified quickly and was progressively supplanted by derived ones after the Early Eocene.

From the plesiomorphic pauciserial decussation, microstructure evolved divergently in the two main rodent clades, Ctenohystrica and Ischyromyiformes (sensu Marivaux et al., 2004; see also Martin, 1993, 1997). In Ctenohystrica, the number of prisms per band increased, while the portio externa became thinner relative to the portio interna. The prisms of the portio externa grew more steeply inclined relative to the OES, and the IPM thinned into sheets between prism rows. These tendencies gave rise multiple times convergently to the multiserial decussation type, which is itself divided into three subtypes according to the decussation angle: IPM parallel to prisms, at an acute angle, or perpendicular. These subtypes are thought to represent a trend in the evolution of multiserial decussation, with parallel IPM being the most primitive and perpendicular most derived (Martin, 1993). Indeed, this likely represents a functional adaptation, as a tendency toward IPM crystallites perpendicular to the prisms decreases the anisotropy of the enamel layer and thus decreases the extent of crack propagation (Koenigswald and Pfretzschner, 1991; Rensberger, 1997).

This evolutionary history of microstructural characters is nigh identical for Ischyromyiformes, leading to the uniserial type, the major difference being that the number of prisms per band decreased until only one remained in the derived types. In this group, cases of convergence with Ctenohystrica are known for some Theridomyidae (Blainvillimys and Archaeomys; Martin, 1999) with "pseudomultiserial" decussation, and Pedetidae (Martin, 1994; Marivaux et al., 2004; Marivaux et al., 2011) with true multiserial decussation; these clades otherwise nest among taxa known for pauciserial, pauciserial with uniserial tendency, and uniserial decussation.

As pauciserial enamel is only observed in early Tertiary rodents, it is, therefore, not possible to segment prisms of this microstructure type with our new methodology. However, we can still use the published $2 \mathrm{D}$ data on fossils and Simulenam for reconstructing the pauciserial decussation in 3D (Fig. 10A), as we did for cetartiodactyls in AlloingSéguier et al. (2017). The basic pauciserial microstructure in Simulenam is characterized by equal "Prism y spacing" and "Prism z spacing," with a value close to one and a half times the value for "Prism diameter" (widely, uniformly spaced prisms, accounting for the thick IPM), little difference in the values of "Prism Secondary Plane" between portio interna and portio externa (prisms in the radial portion moderately inclined relative to the OES). The "Interlacing density" parameter is between three and six, with the values of the "Prism Main Plane" and "Interlaced Main Plane" sets of parameters producing non-orthogonal crossing trajectories (bands of usually three to six prisms and 

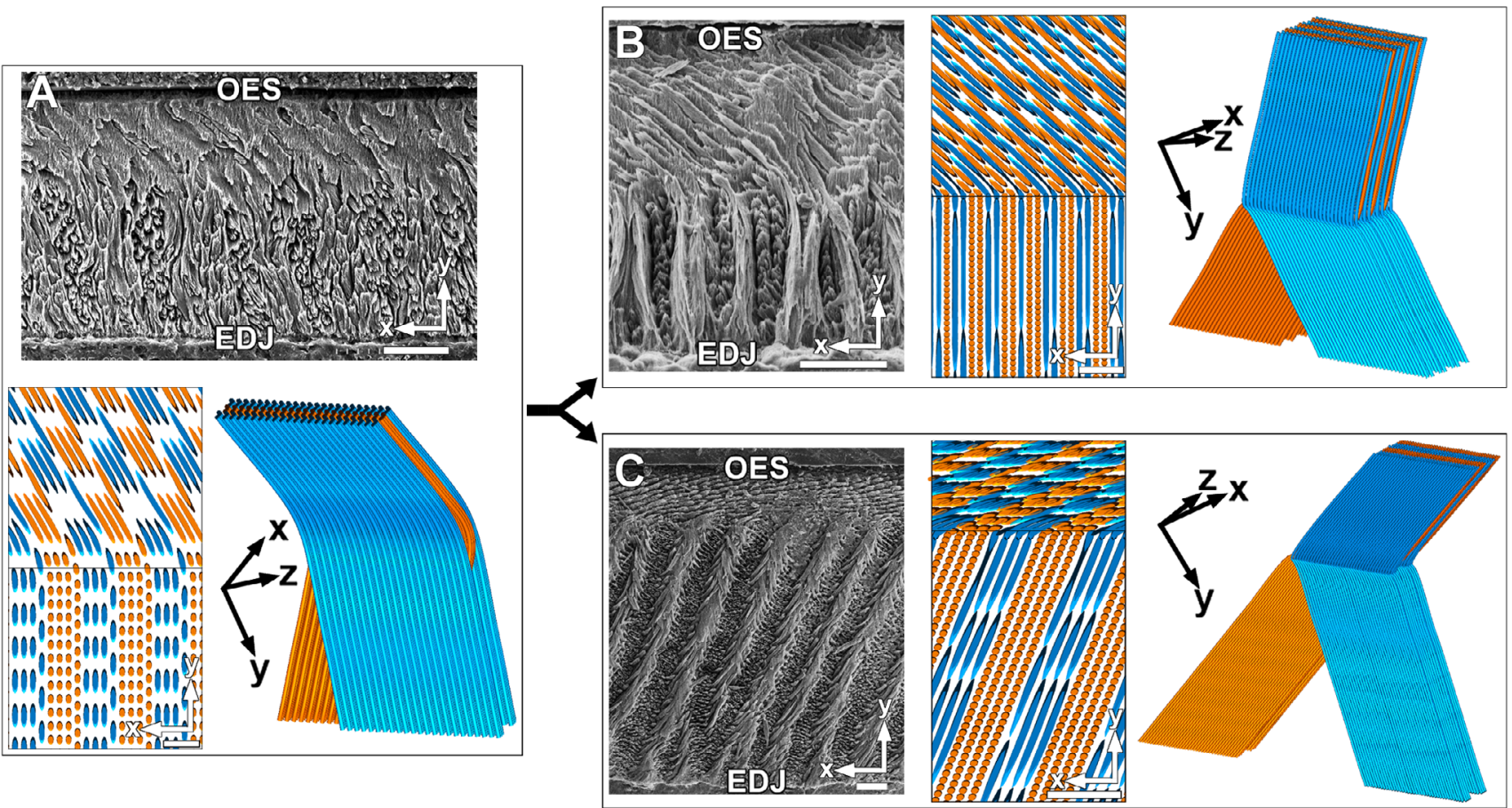

Fig. 10. Comparison between the ancestral pauciserial decussation and more derived, intermediate microstructures between pauciserial and uniserial/multiserial types (black forked arrow symbolizing the divergence of both derived types from the ancestral one); for each model, SEM image (EDJ at the bottom, OES at the top), full 2D cut of the 3D Simulenam simulation, and 3D simulation are presented. (A) Pauciserial decussation of Cocomys sp. (SEM image with courtesy copyright by Thomas Martin; decussation angle: $20^{\circ}$; scale bars: $20 \mu \mathrm{m}$ ); (B) Uniserial tendency of Glibia sp. (decussation angle: $60^{\circ}$; scale bars: $20 \mu \mathrm{m}$ ); (C) Type 1 multiserial decussation of cf. Protophiomys tunisiensis (decussation angle: $65^{\circ}$; scale bars: $20 \mu \mathrm{m})$.

weak decussation angle). Altogether, this enamel type requires almost no modification from an ancestral radial type like the one of Didelphis marsupialis, except for the "Interlaced Main Plane" set of parameters, the bare-bones requirements for the formation of decussation under a crossing model.

Based on the known trajectory of microstructure characters evolution in rodents, supplemented by $2 \mathrm{D}$ data of intermediate forms, it becomes possible to retrace this evolution through Simulenam parameters. For the uniserial type, the zegdoumyid Glibia sp. (Fig. 10B) exhibits a gradual decrease of "Interlacing density" from the typical pauciserial of three/six to one, with numerous irregularities of two- and sometimes three-prisms bands. This uniserial tendency is also characterized by a decrease of "Prism y spacing" and "Prism z spacing," an increase of the difference between values of "Prism Secondary Plane" of portio interna and portio externa, and the values of "Prism Main Plane" and "Interlaced Main Plane" tend toward orthogonal crossing trajectories. Accordingly, for the multiserial type, there is a decrease of "Prism y spacing" and "Prism z spacing," an increase of the difference between values of "Prism Secondary Plane" of portio interna and portio externa, and the values of "Prism Main Plane" and "Interlaced Main Plane" tend toward orthogonal crossing trajectories. As shown by the microstructure of $c f$. Protophiomys tunisiensis (Fig. 10C), the transition from the first forms of multiserial toward more derived ones is also characterized by the increased perpendicularity between the crystallites of the prisms and those of the IPM.
Then, considering the apparent tight links between decussation and cellular mechanisms, as previously proposed, it becomes possible to describe the putative evolution of these mechanisms. The changes in intra- and inter-row distance between prisms ("Prism y spacing" and "Prism z spacing"), and thus, IPM thickness, could be linked to ameloblast width, or morphology and orientation of the Tomes' processes. For a fixed prism diameter, ameloblasts of lesser width would produce more closely packed prisms, leaving less space between them for IPM maturation. However, if prisms are too close to each other, one might expect that this would also impact their allocated maturation space, producing the oval, "squished" prisms of the multiserial and uniserial types instead of a more regular circular cross-section. Regardless of ameloblast width, a similar phenomenon could occur if the Tomes' process, instead of being short and jutting perpendicularly from the cell apex surface (the morphology likely responsible for radial enamel), would grow longer and steeply inclined with respect to the apex (with a "picket fence" appearance, as observed for the rat and the mouse; Warshawsky and Smith, 1974; video S27 in Smith et al., 2016). This would result in neighboring processes being stacked against each other. The sliding of rows, with the process being dragged and bent by the moving ameloblast, could indirectly generate such morphology of the Tomes' process.

The trend toward orthogonal crossing trajectories ("Prism Main Plane" and "Interlaced Main Plane"), indicating an increase of the angle between the two orientation types of 
the portio interna and interpreted as the decussation angle, is likely linked to the extent of the sliding of rows in opposite directions. The quicker the ameloblast is at sliding (the extent of lateral displacement from the starting position at the EDJ), the more inclined the resulting prism will be. The extent and efficiency of the sliding mechanism is probably dependent on the dynamic of the junctional complexes and actin microfilaments intra- and inter-row, although their precise functions with regards to the sliding mechanisms still need to be clarified.

The increase of the difference between values of "Prism Secondary Plane" for the portio interna and the portio externa does not seem to be linked to the sliding of rows but to the global movement of the epithelium, with changes in the migration pattern of the ameloblast layer. This migration was likely relatively homogeneous during amelogenesis for the pauciserial type, from the EDJ toward the OES, while for the uniserial and multiserial types the ameloblast layer undergoes a clear and abrupt shift at the transition from decussated to radial enamel. In the case of multiserial decussation, as segmented here for Myocastor coypus, the direction of the migration shift is quite similar to one of the sliding orientations of the portio interna, as seen with prisms keeping almost the same orientation from portio interna to externa, while prisms of the other orientation experience a substantial change of orientation at $90^{\circ}$ (Fig. 4B). For the uniserial type, as seen for Mus musculus with 2D SEM data, the orientation of prisms in the portio externa is different from the two orientation types of the portio interna. In both cases, the migration shift induces the formation of prisms reaching the OES at low angles, a change that is probably a functional adaptation (the long axis of a prism not being perpendicular to the OES affords better resilience against abrasion forces; Shimizu et al., 2005).

The gradual decrease of "Interlacing density" from three to six prisms per band to only one could be interpreted as an increased, finer control of the sliding mechanism to affect rows individually rather than as groups. Indeed, the transitional pauci-uniserial type presents variability in the number of prisms per band, as seen in the microstructure of Glibia sp., suggesting that the mechanism is less constrained and more prone to variations, while the uniserial type is far more regular, with only occasional and often temporary double rows. The multiserial type is also more regular in the number of prisms per band than the pauciserial (Martin, 1993). In the case of the uniserial type, this likely represents a functional adaptation to improve the resistance of decussation to crack propagation, by increasing heterogeneity and lessening the effects of anisotropy (Rensberger, 2000; Popowics et al., 2004).

As the IPM is not yet directly reconstructed in Simulenam, one character differentiating pauciserial and multiserial/uniserial decussation types could not be explored here, namely the angle of IPM crystallites with prism crystallites (parallel for pauciserial, acute to perpendicular for derived multiserial/uniserial decussation). As the tip of the Tomes' process secretes the prisms and the IPM is secreted by its sides or by the surface of the cell apex not occupied by the process, this difference could be linked to changes in its shape and/or orientation, already suggested as responsible for the changes of IPM thickness.

Finally, a peculiarity of rodent microstructure evolution could be explained by the likely presence of multiple
Tomes' processes for a single ameloblast, as suggested for Myocastor coypus. Indeed, this kind of ameloblast would be unable to produce bands less than three or four prisms thick, constraining the evolutionary potential of multiserial forms toward band thickness reduction. If this Tomes' process morphology is an apomorphy of Ctenohystrica, this would explain why some Ischyromyiformes taxa could convergently develop a multiserial-like decussation, even though uniserial-like decussation did not appear in the Ctenohystrica lineage. Indeed, no known Ctenohystrica taxon ever developed a microstructure convergent with the uniserial type, which would be considered less anisotropic, and thus, more functionally efficient, than the multiserial.

\section{CONCLUSIONS}

We developed a new methodology for visualizing enamel prisms and ameloblasts simultaneously on the same specimen in $3 \mathrm{D}$, based on confocal laser microscopy and segmentation, and we confirmed its effectiveness. This allowed a direct comparison between prism and ameloblast size and organization at different stages of amelogenesis, with the definition of potential cellular mechanisms involved in decussation formation. We also provided a clearer, three-dimensional picture of the microstructure of the sampled taxa. It was then possible to incorporate these data into Simulenam's architecture of geometrical parameters for reconstructing virtual $3 \mathrm{D}$ portions of the different decussation types. By replacing these parameters in the context of microstructure's evolutionary history, and simulating in 3D the morphology of fossil taxa, we retraced the evolution of these parameters and the putative cellular mechanisms behind them.

As we noted, there is numerous clues suggesting how decussation could be generated at the cellular level, by involving specific organization of junctional complexes and microfilaments, but direct, conclusive confirmation is still needed. This would require conducting further analyses of the internal dynamics of the ameloblast layer, as it produces different kinds of enamel types. It would also be of interest to continue exploring the diversity of microstructures across Mammalia, especially decussation, as it is now established that at least two taxa, Cetartiodactyla (Alloing-Séguier et al., 2017) and Rodentia, actually employ different, non-homologous mechanisms of decussation formation, even if they have both been described by the general and oft-used term "HSB" in the past.

\section{ACKNOWLEDGEMENTS}

The authors would like to thank Chantal Ripoll for sample decalcification, Maria-Teresa Alvarez-Martinez and Isabelle Sassetti for decalcification, cryostat, and vibratome experiments from the Experimental Histology Network of Montpellier (RHEM), Chantal Cazevieille for the SEM images from the Montpellier RIO Imaging Platform (MRI, Montpellier, France; Institute for Neurosciences Montpellier, France), and Heiko Richter from LLS Rowiak laboratories for laser microdissection (Germany). Confocal microscopy data used in this study were produced using the MRI platform (Montpellier, France). We are grateful to François Catzeflis and Jean-Jacques Duquesne (ISEM, Montpellier, France) for the gift of opossum and mouse samples, and to Thomas Martin for 
the use of his Cocomys sp. SEM photograph. We are indebted to Stephen Baghdiguian for his advice.

\section{Literature Cited}

Alloing-Séguier L, Lihoreau F, Boisserie JR, Charruault AL, Orliac MJ, Tabuce R. 2014. Enamel microstructure evolution in anthracotheres (Mammalia, Cetartiodactyla) and new insights on hippopotamoid phylogeny. Zool J Linn Soc 171:668-695.

Alloing-Séguier L, Martinand-Mari C, Barczi JF, Lihoreau F. 2017. Linking 2D observations to 3D modeling of enamel microstructurea new integrative framework applied to Hippopotamoidea evolutionary history. J Mammal Evol 24:221-231.

Barthel KU. 2005. Volume Viewer. http://rsb.info.nih.gov/ij/plugins/ volume-viewer.html

Boyde A. 1964. The structure and development of mammalian enamel. Doctoral thesis, Faculty of Medicine (dentistry) of the University of London, London.

Boyde A. 1967. The development of enamel structure. Proc R Soc Med 60:923-928.

Boyde A. 1997. Microstructure of enamel. In: Chadwick DJ, Cardew G, editors. Dental enamel (Ciba Foundation Symposium 205). Chichester: Wiley. p 18-31.

Butcher EO. 1956. Enamel rod matrix formation in the rat's incisor. J Am Dent Assoc 53:707-712.

Du C, Falini G, Fermani S, Abbott C, Moradian-Oldak J. 2005. Supramolecular assembly of amelogenin nanospheres into birefringent microribbons. Science 307:1450-1454.

Fosse G. 1968. A quantitative analysis of the numerical density and the distributional pattern of prisms and ameloblasts in dental enamel and tooth germs. IV. The number of prisms per unit area on the outer surface of human permanent canines. Acta Odontol 26:409-433.

Gardel ML, Schneider IC, Aratyn-Schaus Y, Waterman CM. 2010. Mechanical integration of actin and adhesion dynamics in cell migration. Annu Rev Cell Dev Biol 26:315-333.

Habelitz S. 2015. Materials engineering by ameloblasts. J Dent Res 94:759-767.

Hervé JC, Derangeon M. 2013. Gap-junction-mediated cell-to-cell communication. Cell Tissue Res 352:21-31.

Jasswoin G. 1924. On the structure and development of the enamel in mammals. Quart J Microscop Sci 69:97-118.

Kallenbach E. 1963. The cell web-A fibrillar component of the cytoplasm. Doctoral thesis, McGill University, Montreal.

Kallenbach E. 1973. The fine structure of Tomes' process of rat incisor ameloblasts and its relationship to the elaboration of enamel. Tissue Cell 5:501-524.

Kalthoff DC. 2000. Die Schmelzmikrostruktur in den Incisiven der hamsterartigen Nagetiere und anderer Myomorpha (Rodentia, Mammalia). Palaeontogr Abt A 259:1-193.

Kitajima Y. 2002. Mechanisms of desmosome assembly and disassembly. Clin Exp Dermatol 27:684-690.

Koenigswald W. 2004. Enamel microstructure of rodent molars, classification, and parallelisms, with a note on the systematic affiliation of the enigmatic Eocene rodent Protoptychus. J Mammal Evol 11:127-142.

Koenigswald W, Pfretzschner HU. 1991. Biomechanics in the enamel of mammalian teeth. In: Schmidt-Kittler N, Vogel K, editors. Constructional morphology and evolution. Berlin, Heidelberg: Springer. p 113-125.

Koenigswald W, Holbrook LT, Rose KD. 2011. Diversity and evolution of Hunter-Schreger Band configuration in tooth enamel of perissodactyl mammals. Acta Palaeontol Pol 56:11-32.

Korvenkontio VA. 1934. Mikroskopische Untersuchungen an Nagerincisiven unter Hinweis auf die Schmelzstruktur der Backenzähne: Histologisch-phyletische Studie. Ann Zool Soc Zool-Bot Fenn 'Vanamo' 2:1-274.

Kwon SR, Wertz PW, Li Y, Chan DCN. 2012. Penetration pattern of rhodamine dyes into enamel and dentin: Confocal laser microscopy observation. Int J Cosmet Sci 34:97-101.
Lacruz RS, Smith CE, Kurtz I, Hubbard MJ, Paine ML. 2013. New paradigms on the transport functions of maturation-stage ameloblasts. J Dent Res 92:122-129.

Leblond CP, Warshawsky H. 1979. Dynamics of enamel formation in the rat incisor tooth. J Dent Res 58:950-979.

Lesot H, Hovorakova M, Peterka M, Peterkova R. 2014. Threedimensional analysis of molar development in the mouse from the cap to bell stage. Aust Dent J 59:81-100.

Line SRP, Novaes PD. 2005. The development and evolution of mammalian enamel: Structural and functional aspects. Braz J Morphol Sci 22:67-72.

Maas MC, Dumont ER. 1999. Built to last: The structure, function, and evolution of primate dental enamel. Evol Anthropol 8:133-152.

Margolis HC, Beniash E, Fowler CE. 2006. Role of macromolecular assembly of enamel matrix proteins in enamel formation. J Dent Res 85:775-793.

Marivaux L, Vianey-Liaud M, Jaeger JJ. 2004. High-level phylogeny of early Tertiary rodents: Dental evidence. Zool J Linn Soc 142: 105-134

Marivaux L, Adaci M, Bensalah M, Gomes Rodrigues H, Hautier L, Mahboubi M, Mebrouk F, Tabuce R, Vianey-Liaud M. 2011. Zegdoumyidae (Rodentia, Mammalia), stem anomaluroid rodents from the early to middle Eocene of Algeria (Gour Lazib, Western Sahara): New dental evidence. J Syst Palaeontol 9:563-588.

Marivaux L, Essid EM, Marzougui W, Khayati Ammar H, Adnet S, Marandat B, Merzeraud G, Tabuce R, Vianey-Liaud M. 2014. A new and primitive species of Protophiomys (Rodentia, Hystricognathi) from the late middle Eocene of Djebel el Kébar, Central Tunisia. Palaeovertebrata 38:1-17.

Martin T. 1993. Early rodent incisor enamel evolution: Phylogenetic implications. J Mammal Evol 1:227-254.

Martin T. 1994. African origin of caviomorph rodents is indicated by incisor enamel microstructure. Paleobiology 20:5-13.

Martin T. 1997. Incisor enamel microstructure and systematics in rodents. In: Wv K, Sander PM, editors. Tooth enamel microstructure. Rotterdam: Balkema. p 163-175.

Martin T. 1999. Phylogenetic implications of Glires (Eurymylidae, Mimotonidae, Rodentia, Lagomorpha) incisor enamel microstructure. Mitt Mus Nat kd Berl Zool Reihe 75:257-273.

Martin T. 2007. Incisor enamel microstructure and the concept of Sciuravida. Bull Carnegie Mus Nat Hist 39:127-140.

Meyer W. 1935. Normal histology and histogenesis of the human teeth and associated parts. Philadelphia: JB Lippincott Company.

Nekrasova O, Green KJ. 2013. Desmosome assembly and dynamics. Trends Cell Biol 23:537-546.

Nishikawa S. 2017. Cytoskeleton, intercellular junctions, planar cell polarity, and cell movement in amelogenesis. J Oral Biosci 59: 197-204.

Nishikawa S, Fujiwara K, Kitamura H. 1988. Formation of the tooth enamel rod pattern and the cytoskeletal organization in secretory ameloblasts of the rat incisor. Eur J Cell Biol 47:222-232.

Nylen MU, Eanes ED, Omnell KÅ. 1963. Crystal growth in rat enamel. J Cell Biol 18:109-123.

Osborn JW. 1970a. The mechanism of ameloblast movement: A hypothesis. Calc Tiss Res 5:344-359.

Osborn JW. 1970b. The mechanism of prism formation in teeth: A hypothesis. Calc Tiss Res 5:115-132.

Osborn JW. 1990. A 3-dimensional model to describe the relation between prism directions, parazones and diazones, and the Hunter-Schreger bands in human tooth enamel. Arch Oral Biol 35: 869-878.

Pfretzschner HU. 1993. Enamel microstructure in the phylogeny of the Equidae. J Vertebr Paleontol 13:342-349.

Popowics TE, Rensberger JM, Herring SW. 2004. Enamel microstructure and microstrain in the fracture of human and pig molar cusps. Arch Oral Biol 49:595-605.

Raschkow I. 1835. Meletemata circa mammalium dentium evolutionem. Thèse. Méd. Vratislaviae [Breslau] typis M. Friedlaender, s.d Inaug. Dissert. Wratislaviae.

Rensberger JM. 1997. Mechanical adaptation in enamel. In: Koenigswald WV, Sander PM, editors. Tooth enamel microstructure. Rotterdam: Balkema. p 237-257. 
Rensberger JM. 1999. Enamel microstructure specialization in the canine of the spotted hyean, Crocuta crocuta. Scanning Miscroc 13: 343-361.

Rensberger JM. 2000. Pathways to functional differentiation in mammalian enamel. In: Teaford MF, Smith MM, Ferguson MWJ, editors. Development Function and Evolution of Teeth. New York: Cambridge University Press. p 252-268.

Rensberger JM, Pfretzschner HU. 1992. Enamel structure in astrapotheres and its functional implications. Scanning Microsc 6:495-508.

Runkle EA, Mu D. 2013. Tight junction proteins: From barrier to tumorigenesis. Cancer Lett 337:41-48.

Schindelin J, Arganda-Carreras I, Frise E, Kaynig V, Longair M, Pietzsch T, Preibisch S, Rueden C, Saalfeld S, Schmid B, et al. 2012. Fiji: An open-source platform for biological-image analysis. Nat Methods 9:676-682.

Shimizu D, Macho GA, Spears IR. 2005. Effect of prism orientation and loading direction on contact stresses in prismatic enamel of primates: Implications for interpreting wear patterns. Am J Phys Anthropol 126:427-434.

Simmer JP, Richardson AS, Hu YY, Smith CE, Hu JCC. 2012. A post-classical theory of enamel biomineralization and why we need one. Int J Oral Sci 4:129-134.

Smith CE, Warshawsky H. 1975. Cellular renewal in the enamel organ and the odontoblast layer of the rat incisor as followed by radioautography using ${ }^{3} \mathrm{H}$-thymidine. Anat Rec 183:523-561.

Smith CE, Warshawsky H. 1977. Quantitative analysis of cell turnover in the enamel organ of the rat incisor. Evidence for ameloblast death immediately after enamel matrix secretion. Anat Rec 187 63-97.

Smith CE, Hu Y, Hu JC, Simmer JP. 2016. Ultrastructure of early amelogenesis in wild-type, Amelx-/-, and Enam-/- mice: Enamel ribbon initiation on dentin mineral and ribbon orientation by ameloblasts. Mol Genet Genomic Med 4:662-683.

Stefen C. 1999. Enamel microstructure of recent and fossil Canidae (Carnivora: Mammalia). J Vertebr Paleontol 19:576-587.

Süss W. 1940. Über die Architektur des Schmelzes. Zeitschr F Zellforsch 30:171-193.

Tafforeau P, Zermeno JP, Smith TM. 2012. Tracking cellular-level enamel growth and structure in $4 \mathrm{D}$ with synchrotron imaging. J Hum Evol 62:424-428.

Waldeyer W. 1870. Structure and development of the teeth. In: Stricker S, editor. Manual of human and comparative histology. London: New Sydenham Society. p 463-493.

Warshawsky H. 1978. A freeze-fracture study of the topographic relationship between inner enamel-secretory ameloblasts in the rat incisor. Am J Anat 152:153-207.

Warshawsky H, Smith CE. 1971. A three-dimensional reconstruction of the rods in rat maxillary incisor enamel. Anat Rec 169: $585-591$.

Warshawsky H, Smith CE. 1974. Morphological classification of rat incisor ameloblasts. Anat Rec 179:423-445.

Wolf J. 1942. Einfluss der Ameloblastenvershciebungen auf die Gestalt und den Verlauf der Schmelzprismen. Dtsch Zahn Mund U Kieferheilk 9:488-514.

Yang X, Wang L, Qin Y, Sun Z, Henneman ZJ, Moradian-Oldak J, Nancollas GH. 2010. How amelogenin orchestrates the organization of hierarchical elongated microstructures of apatite. J Phys Chem B 114:2293-2300.

Yuan X, Nishikawa S. 2014. Angular distribution of cross-sectioned cell boundaries at the distal terminal web in differentiating preameloblasts, inner enamel secretory ameloblasts and outer enamel secretory ameloblasts. Microscopy 63:33-39. 